
\title{
28 Research Square \\ Fall Characteristics Among Elderly Populations in Urban and Rural Areas in Korea
}

\section{Myeongkyu Kim}

Hanyang University College of Medicine

\section{Misoo Chang}

Hanyang University

\section{Eunwoo Nam}

Hanyang University

\section{Seul Gi Kim}

Seoul National University Graduate School of Public Health

\section{Sung-il Cho}

Seoul National University Graduate School of Public Health

\section{Dong Hee Ryu}

Kyungpook National University

\section{Sin Kam}

Kyungpook National University School of Medicine

\section{Bo Youl Choi}

Hanyang University College of Medicine

Mi Jung Kim ( $\nabla$ kimmjreh@hanyang.ac.kr)

Hanyang University College of Medicine https://orcid.org/0000-0003-2920-9900

\section{Research article}

Keywords: Fall, Urban, Rural

Posted Date: March 30th, 2020

DOI: https://doi.org/10.21203/rs.3.rs-19363/v1

License: (c) (i) This work is licensed under a Creative Commons Attribution 4.0 International License.

Read Full License

Version of Record: A version of this preprint was published at Medicine on November 13th, 2020. See the published version at https://doi.org/10.1097/MD.0000000000023106. 


\section{Abstract}

\section{Background}

Falling is one of the leading causes of injury among elderly populations. As the population over 65 years old increases, medical costs due to falling will also increase. Urban and rural areas have different fall characteristics, and research into these differences is lacking.

\section{Methods}

A survey was conducted on 2,012 people over 60 years old between September 1, 2015 to October 12, 2015. Guro-gu (Seoul), Yeongdeungpo-gu (Seoul), and Jung-gu (Daegu) were classified as urban areas and included 1,205 of the study participants. Dalseong-gun (Daegu) and Yangpyeong-gun (Gyeonggi-do) were categorized as rural areas and included 807 participants. Several region characteristics, including population density, were considered to distinguish between urban and rural areas. The survey included questions about fall history, cause, season and time of recent falls, and external conditions associated with recent falls, like floor or ground material and shoe types.

\section{Results}

Rural respondents were older than urban respondents $(p<0.001)$ but did not differ significantly in gender proportion ( $p=0.082)$. Fall history over the past year was not different between the two regions $(p=0.693)$, but lifetime fall history was greater among rural respondents $(p<0.001)$. Only $5.1 \%$ of all respondents had undergone fall-prevention education. A slippery floor was the most common cause of falls in both regions, but there was a significant difference in pattern of fall causes $(p<0.001)$. Falls were more frequent in the summer, spring, and the afternoon in urban areas, and in the summer, autumn, and the morning in rural areas. Cement and asphalt were the most common ground materials at the time of falls in both regions, but rural respondents had higher fall rates when walking on soil and when wearing slippers.

\section{Conclusions}

A fall-prevention program that reflects the characteristics and differences of falls in urban and rural areas should be developed and used to effectively prevent falling among elderly people.

\section{Background}

A fall is defined by the World Health Organization as an incident that leads to a person unintentionally coming to rest on the ground, floor or other lower level [1]. Falls can happen at any age, but falls are more common among the elderly than young people. Additionally, elderly people are at greater risk of injury when they fall [2]. A study of the 2014 Behavioral Risk Factor Surveillance System (BRFSS) survey found that $28.7 \%$ people 65 years or older in the United States (29.0 million people) experienced a fall during the past 12 months, and $37.5 \%$ of them (7.0 million people) had injuries that require medical treatment [3]. 
Falls can cause non-life-threatening injuries, such as dislocations, sprains, cuts, and abrasions, but hemorrhage from head injuries and fractures can be fatal. [4-5] Falls are responsible for $98 \%$ of hip fractures [6], and the one-year mortality rate after hip fracture is $8.4 \%-36 \%$, higher than non-hip fracture groups or community-living control populations [7]. A survey of 409 community-dwelling elderly people aged 65 or older in Montreal, conducted from May 1987 to October 1988, reported 197 falls, 91 fallrelated injuries (46.2\%), and three hip fractures out of a total of five fracture cases [8]. Data based only on elderly people who live in assisted-living facilities indicate lower rates of fall-related injuries, but not fewer hip fractures. Based on fall data from 469 elderly people living in residential-care facilities in Sweden in 1997 over a single year, fall-related injuries occurred in one quarter of the 865 falls and 18 hip fractures among 24 total fractures were reported [4].

The number of elderly people and their proportion of the total population is increasing worldwide. The elderly population ( $\geq 65$ years) in Europe is expected to increase from 129.6 million (17.4\%) in 2015 to 196.8 million (27.8\%), and from 54.6 million (15.1\%) in 2015 to 94.6 million (21.4\%) in 2050 in North America. The same trend is seen in other continents, including Asia and Africa [9]. As the elderly population grows, medical expenses due to falls are becoming a great social burden. In the United States, a survey of seniors aged 65 and older reported that the direct medical cost from falls was 616.5 million dollars in 2012 (average cost per fatal fall: 25,487 dollars) and 637.2 million dollars in 2015 (average cost per fatal fall: 26,340 dollars). The direct medical cost from non-fatal falls was 30.3 billion dollars in 2012 (average cost per non-fatal fall: 9,463 dollars) and 31.3 billion dollars in 2015 (average cost per non-fatal fall: 9,780 dollars) [10]. Total and per-fall costs are increasing; thus, efforts are needed to understand and reduce falls in older people.

While studying fall characteristics in various regions, we observed differences between urban and rural areas. To date, most falling research has focused on urban residents. Falling incidence and cost in rural elderly populations have been studied but separately from urban populations [11-12], thus, there have been no studies comparing fall characteristics, such as frequency, cause, time, and shoes worn, between urban and rural areas. This study compared fall characteristics between urban and rural areas using data from a large-scale survey conducted in Korea, and presents basic information for establishing fall-related policies for the elderly.

\section{Methods}

\section{Participants}

This study is based on survey results from people over 60 years old who visited a public health center in their district. The survey was completed by 2,012 people living in five regions of Korea from September 1 , 2015 to October 12, 2015. Among the five regions, Guro-gu (Seoul, n=401), Yeongdeungpo-gu (Seoul, $\mathrm{n}=404$ ), and Jung-gu (Daegu, $\mathrm{n}=400$ ) were classified as urban areas, and Dalseong-gun (Daegu, $\mathrm{n}=400)$ and Yangpyeong-gun (Gyeonggi-do, $n=407$ ) were classified as rural areas.

\section{Urban and rural areas}


The criteria for distinguishing urban and rural areas in the health sciences and sociology fields have changed over time, and various standards currently exist. The United States Census Bureau defines urban areas as residential population densities of more than 1,000 people per square mile in contiguously distributed areas and includes developed areas reflecting other land-use characteristics. Accordingly, all areas that did not meet the criteria for urban were designated as rural [13]. Table 1 compares region characteristics according to urban and rural areas [14]. Dalseong-gun has a population density $\geq 1,000$ people per square mile, but has many differences from other urban areas in our study. And its young population was discontinuously concentrated in a narrow area with many factories. Thus, we decided to classify Dalseong-gun as rural.

\section{Questionnaire}

The questionnaire, written in Korean, included several questions to characterize falls. It excluded questions about personally identifiable information, and only gender and age were recorded. Fallexperience questions, included cause of fall, season and time of day, floor or ground materials, shoe type, and experience with fall-prevention education. Only willing volunteers completed surveys, and informed consent was obtained after providing potential participants with sufficient study information. All participants were additionally informed that they could stop their participation at any time. This study and the questionnaire were approved by the Hanyang University Medical Center Institutional Review Board (No. HYI-15-008-2).

\section{Statistical analyses}

This study analyzed differences in fall characteristics between urban and rural areas using descriptive statistical methods. Handwritten survey responses were transcribed into a database by six researchers who followed consistent data-entry rules. The chi-square test was used to compare demographic data such as age and gender between the urban and rural areas. To compare the characteristics of urban and rural falls, differences were estimated using the chi-square test. Statistical analyses were carried out using SPSS software ver. 21.0 (IBM, Armonk, NY, USA)

\section{Results}

\section{Demographic characteristics}

Of the 2,012 participants in this study, 1,205 lived in urban area and 807 lived in rural areas. Among urban and rural residents, respectively, $36.0 \%$ and $23.4 \%$ were in their $60 \mathrm{~s}, 46.1 \%$ and $52.4 \%$ were in their $70 \mathrm{~s}$, and $17.9 \%$ and $24.2 \%$ were 80 or over. Rural residents were significantly older than urban participants $(p<0.001)$, and $63.4 \%$ and $67.0 \%$ of urban and rural area residents, respectively, were women $(p=0.082$; non-significant). Lifetime fall history was significantly higher in rural areas $(78.9 \%)$ than in urban areas $(69.3 \% ; p<0.001)$. However, fall history during the one year prior to the survey (August 2014 to September 2015) was similar between areas $(p=0.693)$. Ninety-eight people in the urban areas $(8.1 \%)$ and only four people in rural areas $(0.5 \%)$ underwent fall-prevention education at any time in the past, which is a 
significant difference ( $<<0.001$; Table 2). For more detailed demographic data of participants in the study, refer to the results of Lee et al. [15], who presented the fall rate of the elderly in Korea based on the survey conducted in the present study.

\section{Causes of falls}

Among the 663 respondents who experienced a fall in the past year, the most common cause in both urban (32.6\%) and rural (42.1\%) areas was a slippery surface, according to multiple-choice response. In urban areas, stumbling on a door sill (14.0\%) and ankle sprain (13.6\%) were the next common causes. In rural areas, ankle sprain (11.6\%), dizziness (10.6\%), and a steep slope (7.7\%) were the next most common causes. Differences in cause of fall were significant between urban and rural areas in a chi-square test $(p<0.001 ;$ Table 3, Figure 1).

\section{Season and time of fall}

The 663 respondents who experienced a fall in the past year were asked about the month and season their fall occurred. Falls occurred most frequently in the summer (June-August, 29.8\%) and spring (MarchMay, $29.0 \%)$ in urban areas, and in the summer $(27.8 \%)$ and autumn $(26.3 \%)$ in rural areas. Seasonal fall rates were statistically different between the two regions $(p=0.009)$. Regarding time of day, $55.2 \%$ of falls occurred in the afternoon (12:00 PM-18:00 PM) in urban areas, and $45.9 \%$ of falls occurred in the morning (06:00 AM-12:00 PM) in rural areas. The fall rate according to time of day was significantly different between the two areas $(p<0.001$; Table 4, Figures $2 \& 3)$.

\section{Floor or ground material and shoes type}

As above, the 663 people who experienced a fall in the past year were asked about the floor or ground material where they fell. Roads made of cement or asphalt were the most common ground materials at the time of the fall in both urban (38.7\%) and rural (37.8\%) areas. Soil (20.1\%), tile (15.3\%), linoleum $(13.7 \%)$, and ice $(5.1 \%)$ were the next common materials in urban areas, while soil (30.0\%), linoleum $(13.0 \%)$, tile (10.0\%) and ice (4.1\%) were the next common in rural areas; the differences between urban and rural areas were significant $(\mathrm{p}=0.008)$. When asked about shoes worn at the time of the fall, $58.0 \%$ of urban and $45.2 \%$ of rural respondents reported running shoes. Other responses were barefoot $(18.1 \%)$, slippers $(11.2 \%)$, and dress shoes $(4.6 \%)$ in urban areas, and slippers $(22.6 \%)$, barefoot $(16.3 \%)$, and dress shoes $(3.3 \%)$ in rural areas, and the difference between urban and rural areas was significant $(p<0.001$; Table 5, Figures 4 \& 5).

\section{Discussion}

In this study, we compared fall characteristics between urban and rural areas over the same time period, and found significant differences in lifetime fall history, cause of falls, time of day, and shoes worn. Rural participants were statistically older than urban participants, and this difference was reflected in the insignificantly higher proportion of female respondents in the rural subset. Differences in age and gender 
composition are a result of differences in demographic structure and industrial characteristics between urban and rural areas. Population data for 2014 showed that people over 60 years comprised $15.7 \%$ of urban communities and $19.8 \%$ of rural communities [14].

We did not find a statistical difference in the fall rate over the previous year between urban and rural areas, which is in line with other studies. A 2014 study of Australians over 50 years found no difference in fall hospitalizations, fall mortality, or fall-related injuries between city and rural participants [11]. However, we found that lifetime fall history was higher in rural areas, perhaps because the average age of our rural participants was higher than of urban participants. Also, it is thought that there are many people in rural areas who fall, including those younger than 60 years, due to environmental differences, and this is one of the causes for higher lifetime fall history in rural areas.

People in urban and rural areas typically use different medical services after falling because of disparities in medical accessibility. Byles et al. [16] found that fall patients were more likely to be treated by general practitioners and specialists in urban areas, while non-urban patients usually accessed community services and alternative health practitioners. Therefore, it is particularly important to provide good fallprevention education in rural areas. However, as shown in Table 1 and 2, despite rural areas having higher ratios of elderly welfare facilities to senior residents, fewer rural respondents had received fall-prevention education than urban respondents.

The effectiveness of fall-prevention interventions has been demonstrated in a number of studies. A 27month survey of people over 65 years old in Denmark, including 12,905 people who underwent fallprevention education and 11,460 control participants showed that all types of fracture injuries were reduced in the intervention group, especially lower-extremity fractures, which decreased by $33 \%$ [5]. HillWestmoreland et al. [17] showed that the fall rate was $4 \%$ lower among intervention groups compared with control groups in a meta-analysis of 12 studies. Additionally, the effect was stronger when risk modification and comprehensive risk assessment were performed simultaneously, rather than exercise alone. Therefore, fall-prevention efforts are a necessary part of an educational program, which should also address issues elucidated by our above-mentioned results, including causes, characteristics, and risk factors for urban and rural populations.

We found that slippery floors were the leading cause of falls in both urban and rural areas, which is consistent with findings from the United States and China [18-19]. However, we also found that slipping rates were higher in rural areas than cities and stumbling on door sills was more common in urban areas. These findings should be taken into account when designing public buildings or facilities related to elderly citizens. Also, because falls caused by collisions are more common in urban areas, this should be emphasized in urban fall-prevention education.

Both urban and rural participants in this study experienced the most falls during summer, a finding that differed from other studies. Bulajic-Kopjar [20] analyzed 10,992 fall-related fractures in Norwegian 65 years and older, and found that the risk of falling was greater during the colder months for people 65-79 years old and for people over 80 years. Furthermore, the fractures that occurred during the winter were 
mostly caused by ice and snow, and the rate of hip and arm fractures also increased. Caberlon et al. [21] studied people over 60 years old in Rio Grande do Sul of Brazil, a temperate region, and also found that the largest number of falls occurred during winter (26.8\%), and $34 \%$ of all fractures occurred in winter as well. In Korea, falls are concentrated in the season with increased outdoor activity. However, almost $25 \%$ of falls still occur in winter, and winter falls carry the highest injury risk, thus, interventions to prevent winter falls are very important.

This is the first study to compare the time of fall occurrence between urban and rural areas. As shown in Table 4, falls were concentrated in the afternoon in urban areas, and in the morning in rural areas. The low fall rates at night in urban and rural areas seem to be related to the low proportion of low lighting in the causes of falls. However, the smaller number of night-time falls is likely partially attributed to less outdoor activity and does not necessarily indicate adequate lighting. Although some researchers expected better lighting to minimize falls [22], most studies have been performed only in indoor environments [23], and further research is needed on the relationship between lighting and falls.

We also evaluated whether there was a difference in the floor or ground materials during falls in urban and rural areas. Both had the highest number of falls on cement or asphalt. However, in rural areas, the rate of falls on soil was higher than in urban areas, possibly indicating that falls in rural areas frequently happen while performing farming activities, which is consistent with previous studies [19]. In the United States, a study of people 65 and older found the highest rate of falls occurred while working around the houses or yard (29\%) [18]. This suggests that, for rural elderly people, particular attention should be paid to falls that occur during economic activities, such as farming, and to falls that occur on ordinary roads. Previously, there were few data about floor or ground materials with regard to elderly fall risk. One study of students on a playground found that the fall rate was highest on asphalt [24].

Most urban and rural respondents in our study reported wearing running shoes at the time of their fall, but the proportion who fell in slippers was higher among rural people than urban people. Sherrington et al. [25] found that, among 95 patients with hip-fracture patients, the largest number was wearing slippers when they fell. Therefore, special attention in rural areas should be paid to safety while wearing slippers. They also found that $75 \%$ of survey participants suffered falls when wearing shoes with sub-optimal features such as no fixation or an excessively flexible heel or sole [25]. Recently, shoes that sound an alarm when approaching an obstacle have been developed to reduce falls [26], but fall-prevention education should include instruction on how to wear them properly.

This paper has several limitations. First, we only included elderly subjects who were able to visit public health centers; thus, we did not collect data from people who were severely injured by falling. Second, because this is a cross-sectional study with a survey design, a recall bias may have been present for many items about past falls. Future research should include further analyses of fall characteristics between urban and rural areas, such as injury type, medical institution attendance, and medical care cost. Also, future studies should include a larger patient sample for more robust results. 


\section{Conclusions}

In this study, we compared fall characteristics between urban and rural areas. The rural participant group was older than the urban group. While the previous-year fall rate was not different between the two groups, lifetime fall history was higher in the rural group. Falls most frequently occurred on slippery floors in both areas. Falls occurred most often in summer and spring in cities, and in summer and autumn in rural areas. Fall occurred most often in the afternoon in urban areas and in the morning in rural areas. Falls on soil and falls in slippers were more common in rural areas than urban areas. Because the proportion of elderly people who received fall-prevention education was low in both urban and rural areas, relevant policies to institute intervention programs that reflect the fall characteristics of urban and rural areas are immediately necessary.

\section{Declarations}

\section{Ethical approval and consent to participate}

This study was approved by the Hanyang University Medical Center Institutional Review Board (No. HYI15-008-2).

\section{Consent for publication}

Written informed consent was obtained for publication of this research.

\section{Availability of data and materials}

The datasets used for this study are available from the corresponding author upon reasonable request.

\section{Competing interests}

The authors declare that they have no competing interests.

\section{Funding}

This research was supported by an R\&D grant (No. 2015005) on rehabilitation from Korea National Rehabilitation Center Research Institute, Ministry of Health \& Welfare.

\section{Authors' contributions}

MK and MJK were involved in drafting and revising the manuscript. MC and EN contributed significantly to statistical analyses. Data collection and management were handled by SGK and SC in Seoul, DHR and SK in Daegu, and BYC in Yangpyeong-gun. All authors made substantial contributions to the conception, design, and data acquisition and analyses for this study. All authors read and approved the final manuscript. 
Acknowledgements

Not applicable.

\section{References}

1. WHO. Falls. 2018. https://www.who.int/en/news-room/fact-sheets/detail/falls. accessed 14 Feb 2020.

2. Freiberger E, Blank WA, Salb J, Geilhof B, Hentschke C, Landendoerfer P et al. Effects of a complex intervention on fall risk in the general practitioner setting: a cluster randomized controlled trial. Clin Interv Aging 2013;8:1079-88.

3. Bergen G, Stevens MR, Burns ER. Falls and Fall Injuries Among Adults Aged $\geq 65$ Years - United States, 2014. MMWR Morb Mortal Wkly Rep. 2016 Sep 23;65(37):993-998.

4. Sadigh S, Reimers A, Andersson R, Laflamme L. Falls and fall-related injuries among the elderly: a survey of residential-care facilities in a Swedish municipality. J Community Health. 2004 Apr;29(2):129-40.

5. Arne Poulstrup, Bernard Jeune. Prevention of fall injuries requiring hospital treatment among community-dwelling elderly. Eur J Public Health. 2000 Mar;10(1):45-50.

6. Parkkari J, Kannus P, Palvanen M, Natri A, Vainio J, Aho H, Vuori I, Järvinen M. Majority of hip fractures occur as a result of a fall and impact on the greater trochanter of the femur: a prospective controlled hip fracture study with 206 consecutive patients. Calcif Tissue Int, 1999;65:183-7.

7. Abrahamsen B, van Staa T, Ariely R, Olson M, Cooper C. Excess mortality following hip fracture: a systematic epidemiological review. Osteoporos Int. 2009 Oct;20(10):1633-50.

8. O'Loughlin JL, Robitaille Y, Boivin JF, Suissa S. Incidence of and risk factors for falls and injurious falls among the community-dwelling elderly. Am J Epidemiol. 1993 Feb 1;137(3):342-54.

9. He W, Goodkind D, Kowal P. U.S. Census Bureau. International population reports, An Aging World: 2015. Washington, U.S. Government Publishing Office, 2016.

10. Burns ER, Stevens JA, Lee R. The direct costs of fatal and non-fatal falls among older adults - United States. J Safety Res. 2016 Sep;58:99-103.

11. Boehm J, Franklin RC, King JC. Falls in rural and remote community dwelling older adults: a review of the literature. Aust J Rural Health. 2014 Aug;22(4):146-55.

12. Lee SG, Kam S. Incidence and estimation of socioeconomic costs of falls in the rural elderly population. J Korean Geriatr Soc 2011;15:8-19.

13. Ratcliffe M, Burd C, Holder H, Fields A. Defining Rural at the US Census Bureau ACSGEO-1. Washington, DC: US Census Bureau; 2016.

14. Korean Statistical Information Service. 2020. http://kosis.kr/statisticsList/statisticsListlndex.do? menuld=M_01_01\&vwcd=MT_ZTITLE\&parmTabld=M_01_01\#SelectStatsBoxDiv. Accessed 3 March 2020. 
15. Lee YG, Kim SC, Chang M, Nam E, Kim SG, Cho SI, Ryu DH, Kam S, Choi BY, Park SB, Kim MJ. Complications and Socioeconomic Costs Associated With Falls in the Elderly Population. Ann Rehabil Med. 2018 Feb;42(1):120-129.

16. Byles J, Powers J, Chojenta C, Warner-Smith P. Older women in Australia: ageing in urban, rural and remote environments. Australasian Journal on Ageing. 2006 Sep;25(3): 151-157.

17. Hill-Westmoreland EE, Soeken K, Spellbring AM. A Meta-Analysis of Fall Prevention Programs for the Elderly: How Effective Are They? Nurs Res. 2002 Jan-Feb;51(1):1-8.

18. Schiller JS, Kramarow EA, Dey AN. Fall injury episodes among noninstitutionalized older adults: United States, 2001-2003. Adv Data. 2007 Sep 21;(392):1-16.

19. Li FF, Zhou DD, Ye ZF, Ren J, Xue C, Peng JJ, Wang SM. Epidemiologic characteristics of fall in the elderly in urban and rural areas in Shanghai. Zhonghua Liu Xing Bing Xue Za Zhi. 2019 Jul 10;40(7):779-785.

20. Bulajic-Kopjar M. Seasonal variations in incidence of fractures among elderly people. Inj Prev. 2000 Mar;6(1):16-9.

21. Caberlon IC, Bós ÂJ. Seasonal differences in falls and fractures among the elderly in the southern Brazilian state of Rio Grande do Sul. Cien Saude Colet. 2015 Dec;20(12):3743-52.

22. Kooijman AC, Cornelissen FW. Better lighting to reduce falls and fracture? A comment on de Boer et al. (2004): different aspects of visual impairment as risk factors for falls and fractures in older men and women. J Bone Miner Res. 2005;20(11):2061-2.

23. Chari SR, Smith S, Mudge A, Black AA, Figueiro M, Ahmed M, Devitt M, Haines TP. Feasibility of a stepped wedge cluster RCT and concurrent observational sub-study to evaluate the effects of modified ward night lighting on inpatient fall rates and sleep quality: a protocol for a pilot trial. Pilot Feasibility Stud. 2016 Jan 7;2:1.

24. Sosin DM, Keller P, Sacks JJ, Kresnow M, van Dyck PC. Surface-specific fall injury rates on Utah school playgrounds. Am J Public Health. 1993 May;83(5):733-5.

25. Sherrington C, Menz HB. An evaluation of footwear worn at the time of fall-related hip fracture. Age Ageing. 2003 May;32(3):310-4.

26. Lin TH, Yang CY, Shih WP. Fall Prevention Shoes Using Camera-Based Line-Laser Obstacle Detection System. J Healthc Eng. 2017;2017:8264071.

\section{Tables}

\section{Table 1. Characteristics of survey areas}




\begin{tabular}{|c|c|c|c|c|c|}
\hline & \multicolumn{3}{|c|}{ Urban area } & \multicolumn{2}{|c|}{ Rural area } \\
\hline & $\begin{array}{l}\text { Guro-gu } \\
\text { (Seoul) }\end{array}$ & $\begin{array}{l}\text { Yeongdeungpo- } \\
\text { gu (Seoul) }\end{array}$ & $\begin{array}{l}\text { Jung-gu } \\
\text { (Daegu) }\end{array}$ & $\begin{array}{l}\text { Yangpyeong- } \\
\text { gun } \\
\text { (Gyeonggi- } \\
\text { do) }\end{array}$ & $\begin{array}{c}\text { Dalseong- } \\
\text { gun } \\
\text { (Daegu) }\end{array}$ \\
\hline $\begin{array}{c}\text { Population density } \\
\text { (people per square mile) }\end{array}$ & $58,844.5$ & $44,498.6$ & $29,204.7$ & 315.1 & $1,123.5$ \\
\hline $\begin{array}{l}\text { Total population } \\
\text { (people) }\end{array}$ & 457,131 & 421,436 & 79,610 & 106,774 & 189,346 \\
\hline $\begin{array}{l}\text { Farming household } \\
\text { (families) }\end{array}$ & 0 & 0 & 0 & 8,326 & 6,566 \\
\hline $\begin{array}{c}\text { Number of senior welfare facilities } \\
\text { per } 1,000 \text { elderly people }\end{array}$ & 2.73 & 2.84 & 2.51 & 11.97 & 9.46 \\
\hline
\end{tabular}

Table 2. Demographic characteristics and prior fall-prevention education in urban and rural areas

\begin{tabular}{|c|c|c|c|}
\hline & $\begin{array}{l}\text { Urban area* (\%) } \\
\quad(n=1205)\end{array}$ & $\underset{(\mathrm{n}=807)}{\text { Rural area }^{\dagger}(\%)}$ & $\begin{array}{l}\text { Total (\%) } \\
(\mathrm{N}=2012)\end{array}$ \\
\hline \multicolumn{4}{|l|}{ Age } \\
\hline $60-69$ & $434(36.0)$ & $189(23.4)$ & $623(31.0)$ \\
\hline $70-79$ & $555(46.1)$ & $423(52.4)$ & 978 (48.6) \\
\hline$\geq 80$ & $216(17.9)$ & $195(24.2)$ & $411(20.4)$ \\
\hline \multicolumn{4}{|l|}{ Gender } \\
\hline Male & 439 (36.4) & $263(32.6)$ & 702 (34.9) \\
\hline Female & $764(63.4)$ & $541(67.0)$ & $1,305(64.9)$ \\
\hline No answer & $2(0.2)$ & $3(0.4)$ & $5(0.3)$ \\
\hline \multicolumn{4}{|l|}{ Lifetime fall history } \\
\hline Yes & 835 (69.3) & 637 (78.9) & $1,472(73.2)$ \\
\hline No & $370(30.7)$ & $170(21.1)$ & $540(26.8)$ \\
\hline \multicolumn{4}{|c|}{ Fall history (past 1 year) } \\
\hline Yes & $393(32.6)$ & $270(33.5)$ & $663(33.0)$ \\
\hline No & $812(67.4)$ & $537(66.5)$ & $1349(67.1)$ \\
\hline \multicolumn{4}{|c|}{ Fall-prevention education } \\
\hline Yes & $98(8.1)$ & $4(0.5)$ & $102(5.1)$ \\
\hline No & $1,078(89.5)$ & 769 (95.3) & $1,847(91.8)$ \\
\hline No answer & $29(2.4)$ & $34(4.2)$ & $63(3.1)$ \\
\hline
\end{tabular}

* Data from Guro-gu (Seoul), Yeongdeungpo-gu (Seoul), and Jung-gu (Daegu) were included.

${ }^{\dagger}$ Data from Yangpyeong-gun (Gyeonggi-do) and Dalseong-gun (Daegu) were included.

Table 3. Fall causes in urban and rural areas over the past year (duplicate responses included) 


\begin{tabular}{lccc}
\hline & Urban area* (\%) $^{*}$ & Rural area $^{\dagger}$ (\%) & Total (\%) $^{(\%)}$ \\
\hline Slippery floor & $154(32.6)$ & $131(42.1)$ & $285(36.4)$ \\
Spraining ankle & $64(13.6)$ & $36(11.6)$ & $100(12.8)$ \\
Stumbling over door sill & $66(14.0)$ & $23(7.4)$ & $89(11.4)$ \\
Collision & $49(10.4)$ & $23(7.4)$ & $72(9.2)$ \\
Dizziness & $28(5.9)$ & $33(10.6)$ & $61(7.8)$ \\
Steep slope & $21(4.5)$ & $24(7.7)$ & $45(5.8)$ \\
Fell down stairs & $28(5.9)$ & $9(2.9)$ & $37(4.7)$ \\
Dark lighting & $17(3.6)$ & $9(2.9)$ & $26(3.3)$ \\
Impaired eyesight & $6(1.3)$ & $4(1.3)$ & $10(1.3)$ \\
Other & $39(8.3)$ & $19(6.1)$ & $58(7.4)$ \\
\hline
\end{tabular}

* Data from Guro-gu (Seoul), Yeongdeungpo-gu (Seoul), and Jung-gu (Daegu) were included.

† Data from Yangpyeong-gun (Gyeonggi-do) and Dalseong-gun (Daegu) were included.

Table 4. Season and time of falls in urban and rural areas over the past year

\begin{tabular}{|c|c|c|c|}
\hline & $\begin{array}{l}\text { Urban area* (\%) } \\
\qquad(\mathrm{n}=393)\end{array}$ & $\underset{(\mathrm{n}=270)}{\text { Rural area }^{\dagger}(\%)}$ & $\begin{array}{l}\text { Total (\%) } \\
(n=663)\end{array}$ \\
\hline \multicolumn{4}{|l|}{ Season } \\
\hline $\begin{array}{c}\text { Spring } \\
\text { (March-May) }\end{array}$ & $114(29.0)$ & 58 (21.5) & $172(25.9)$ \\
\hline $\begin{array}{l}\text { Summer } \\
\text { (June-August) }\end{array}$ & 117 (29.8) & 75 (27.8) & $192(29.0)$ \\
\hline $\begin{array}{c}\text { Autumn } \\
\text { (September-November) }\end{array}$ & 64 (16.3) & 71 (26.3) & $135(20.4)$ \\
\hline $\begin{array}{c}\text { Winter } \\
\text { (December-February) }\end{array}$ & $98(24.9)$ & $66(24.4)$ & $164(24.7)$ \\
\hline \multicolumn{4}{|l|}{ Time } \\
\hline $\begin{array}{c}\text { Dawn } \\
(00: 00-06: 00)\end{array}$ & $24(6.1)$ & $9(3.3)$ & $33(5.0)$ \\
\hline $\begin{array}{c}\text { Morning } \\
(06: 00-12: 00)\end{array}$ & $98(24.9)$ & $124(45.9)$ & $222(33.5)$ \\
\hline $\begin{array}{l}\text { Afternoon } \\
(12: 00-18: 00)\end{array}$ & $217(55.2)$ & $118(43.7)$ & 335 (50.5) \\
\hline $\begin{array}{c}\text { Night } \\
(18: 00-24: 00)\end{array}$ & 42 (10.7) & $12(4.5)$ & $54(8.1)$ \\
\hline No answer & $12(3.1)$ & $7(2.6)$ & 19 (2.9) \\
\hline
\end{tabular}

* Data from Guro-gu (Seoul), Yeongdeungpo-gu (Seoul), and Jung-gu (Daegu) were included.

${ }^{\dagger}$ Data from Yangpyeong-gun (Gyeonggi-do) and Dalseong-gun (Daegu) were included.

Table 5. Floor or ground materials and shoe type at the time of falling in urban and rural areas over the past year 


\begin{tabular}{cccc}
\hline & $\begin{array}{c}\text { Urban area* }(\%) \\
(\mathrm{n}=393)\end{array}$ & $\begin{array}{c}\text { Rural area }^{\dagger}(\%) \\
(\mathrm{n}=270)\end{array}$ & $\begin{array}{c}\text { Total (\%) } \\
(\mathrm{n}=663)\end{array}$ \\
\hline Floor or ground materials & $152(38.7)$ & $102(37.8)$ & $254(38.3)$ \\
Cement, asphalt & $79(20.1)$ & $81(30.0)$ & $160(24.1)$ \\
Soil & $54(13.7)$ & $35(13.0)$ & $89(13.4)$ \\
Linoleum & $60(15.3)$ & $27(10.0)$ & $87(13.1)$ \\
Tile & $20(5.1)$ & $11(4.1)$ & $31(4.7)$ \\
Ice & $13(3.3)$ & $2(0.7)$ & $15(2.3)$ \\
Cannot recall & $11(2.8)$ & $12(4.4)$ & $23(3.5)$ \\
Other & $4(1.0)$ & $0(0.0)$ & $4(0.6)$ \\
No answer & $228(58.0)$ & $122(45.2)$ & $350(52.8)$ \\
Shoe type & $71(18.1)$ & $44(16.3)$ & $115(17.4)$ \\
Running shoes & $44(11.2)$ & $61(22.6)$ & $105(15.8)$ \\
Barefoot & $18(4.6)$ & $9(3.3)$ & $27(4.1)$ \\
Slippers & $2(0.5)$ & $5(1.9)$ & $7(1.1)$ \\
Dress shoes & $26(6.6)$ & $28(10.4)$ & $54(8.1)$ \\
Cannot recall & $4(1.0)$ & $1(0.4)$ & $5(0.8)$ \\
Other & & &
\end{tabular}

* Data from Guro-gu (Seoul), Yeongdeungpo-gu (Seoul), and Jung-gu (Daegu) were included. † Data from Yangpyeong-gun (Gyeonggi-do) and Dalseong-gun (Daegu) were included.

Figures

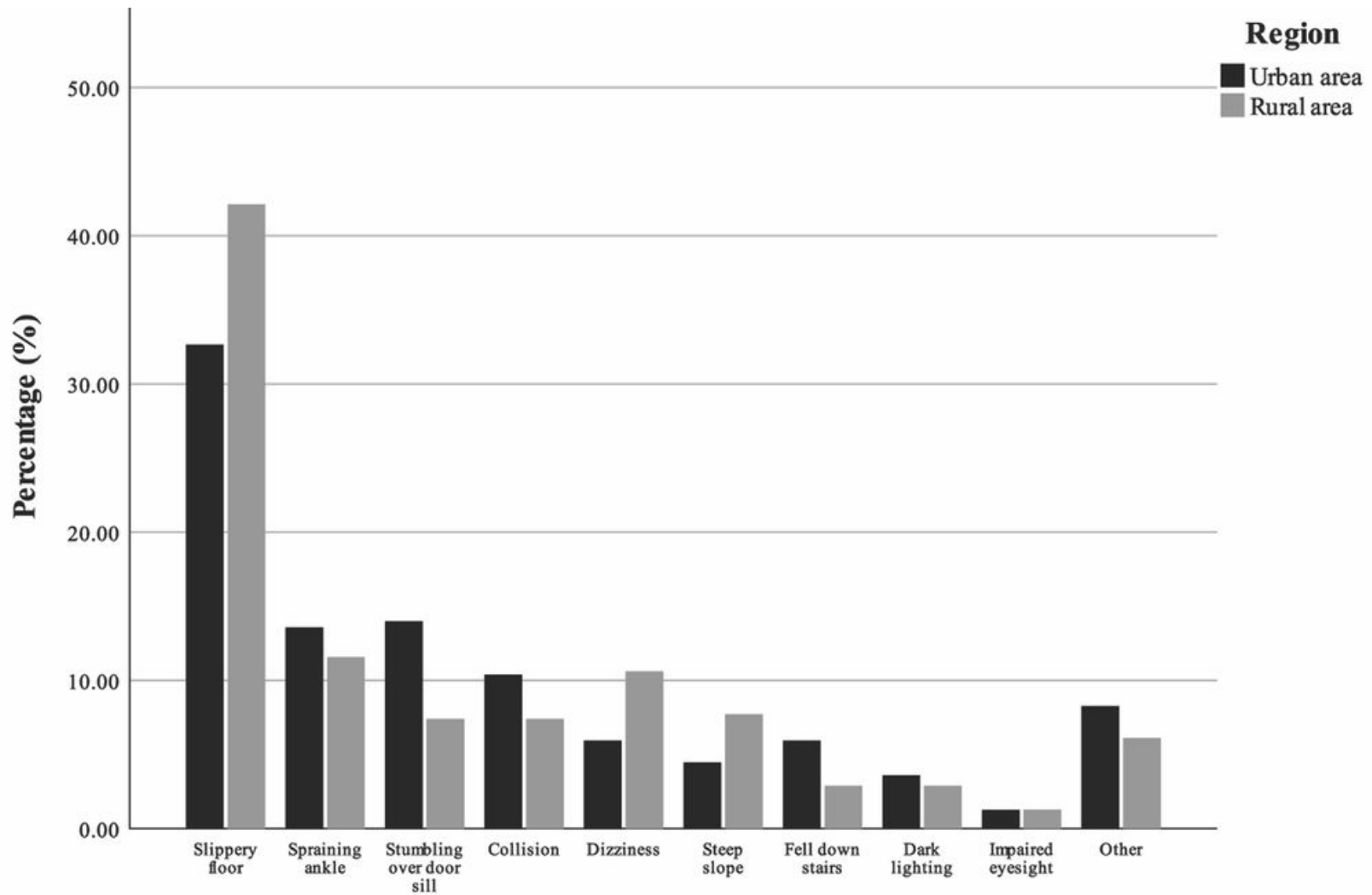

Fall causes

Figure 1 
Comparison of fall causes between urban and rural areas

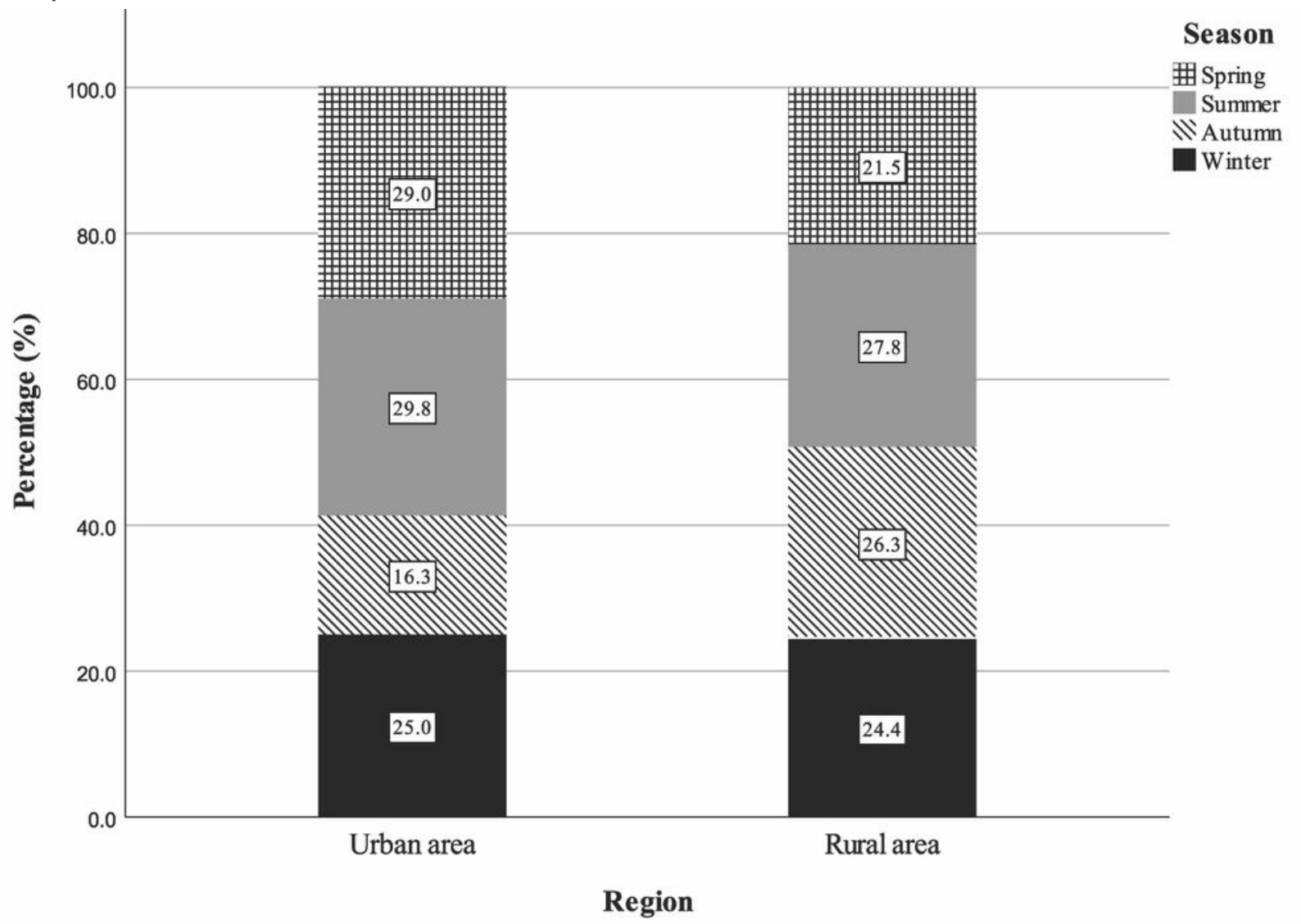

Figure 2

Comparison of seasons when falls occurred between urban and rural areas 


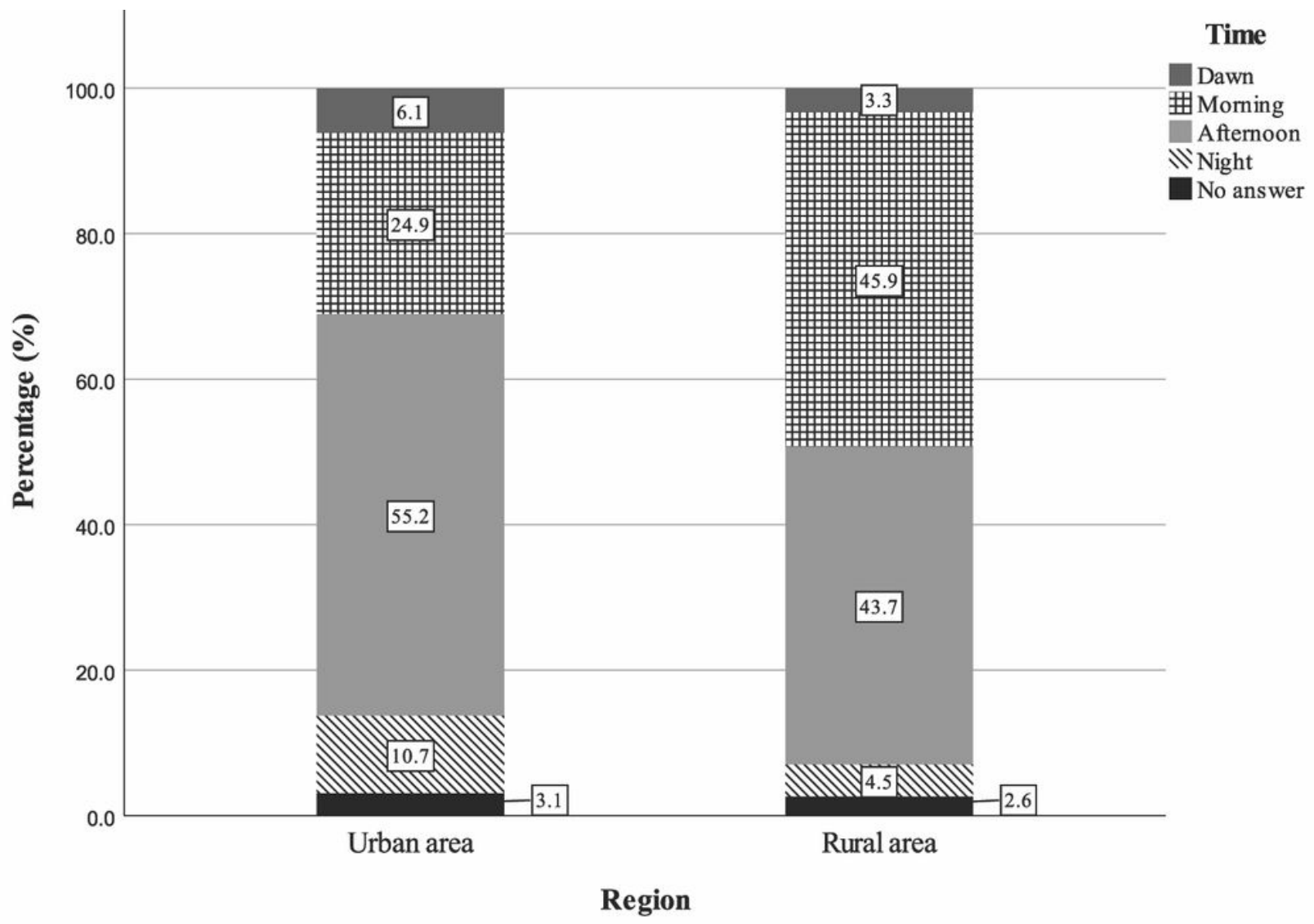

Figure 3

Comparison of the times of day when falls occurred between urban and rural areas 


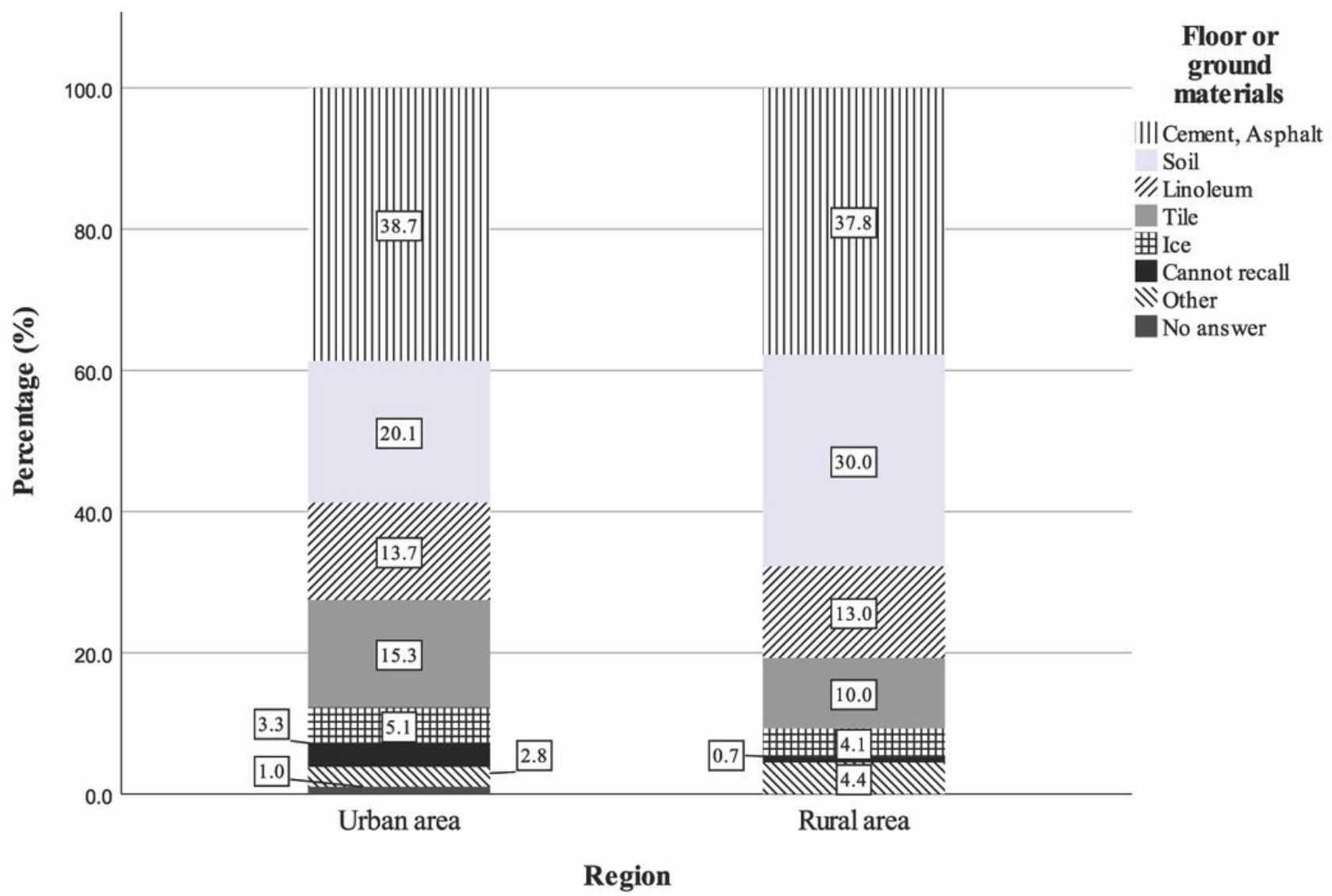

Figure 4

Comparison of floor or ground materials when falls occurred between urban and rural areas 


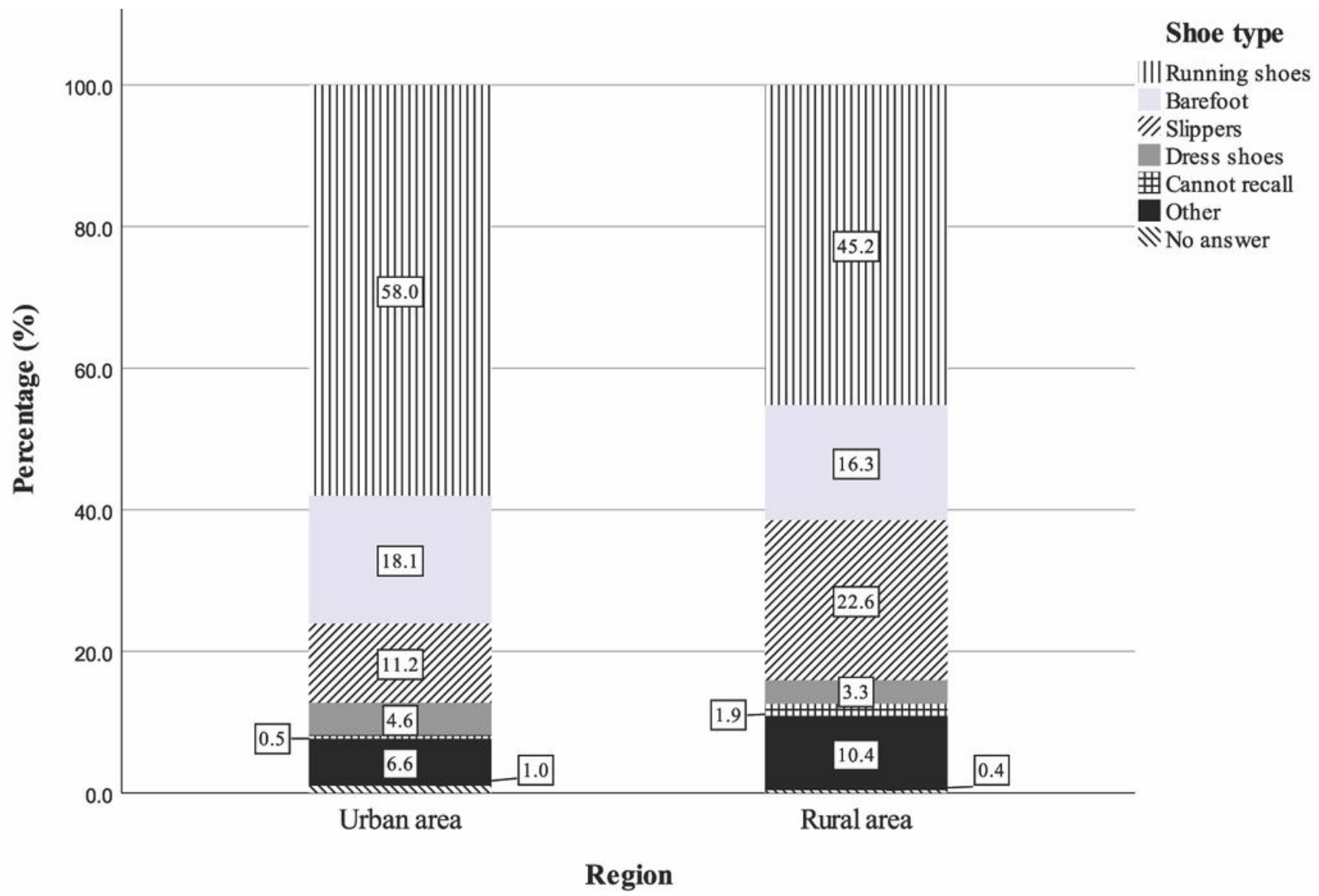

Figure 5

Comparison of shoe type when falls occurred between urban and rural areas 